\title{
ETNOMATEMATIKA: EKSPLORASI BUDAYA SASAK SEBAGAI SUMBER BELAJAR MATEMATIKA SEKOLAH DASAR
}

\author{
Asri Fauzi ${ }^{1 *}$, Aisa Nikmah Rahmatih ${ }^{1}$, Muhammad Sobri ${ }^{1}$, \\ Radiusman $^{1}$, Arif Widodo ${ }^{1}$ \\ ${ }^{1}$ Universitas Mataram \\ Corresponding Author: aisanikmabrahma07@unram.ac.id
}

\begin{abstract}
The purpose of this research is to describe the results of the exploration of ethnomathematics of Sasak culture that can be used as a source of learning mathematics. This type of research is exploratory qualitative research with an ethnographic approach. This research focuses on buildings, crafts, arts, and traditional snacks. The research instrument is the researcher himself. While the method of data collection by interview, field studies, and documentation. Data analysis techniques with triangulation are data reduction, data presentation, and drawing conclusions. The results showed that Sasak cultural products can be used as a source of learning mathematics, especially on the elements of geometry including rectangles, triangles, trapezoid, circles, rhombus, laying-kites, cones, cylinders, and pyramid. Learning resources derived from Sasak culture, if properly utilized, will create meaningful mathematics learning for students.
\end{abstract}

Keywords: Ethnomathematics; Learning resource; Sasak culture

How to cite: Fauzi, A., Rahmatih, A. N., Sobri, M., Radiusman, R., \& Widodo, A. (2020). Etnomatematika: Eksplorasi Budaya Sasak sebagai Sumber Belajar Matematika Sekolah Dasar. JRPM Jurnal Review Pembelajaran Matematika), 5(1), 1-13.

\section{PENDAHULUAN}

Budaya dan Pendidikan merupakan dua unsur yang tidak dapat dipisahkan dalam kehidupan sehari-hari, karena budaya sangat melekat dengan masyarakat dan pendidikan merupakan kebutuhan bagi setiap masyarakat. Juniadi (2015) dan Budiarto (2016) menyatakan bahwa pendidikan merupakan kebutuhan bagi setiap individu tidak dapat terlepas dari budaya dimana kedua komponen tersebut merupakan suatu kesatuan yang berlaku dalam kehidupan sehari-hari setiap manusia. Pendidikan yang berkualitas adalah pendidikan yang tidak melupakan unsur budaya didalamnya, sehingga budaya yang diwariskan dari generasi sebelumnya tidak hilang dengan perkembangan zaman yang begitu pesat. Oleh karena itu penting sekali pendidikan yang berbasis budaya lokal diterapkan pada instansi pendidikan, karena pendidikan yang berbasis budaya lokal sangat membantu siswa untuk membentuk karakter setiap individu. Pradana (2016) juga mengatakan bahwa pendidikan bukan sekedar sarana untuk mentransfer ilmu pengetahuan melainkan juga sebagai wadah untuk membentuk karakter individu dengan mengaitkan unsur budaya dalam pendidikan. 
Cara memperkenalkan budaya kepada siswa dalam pendidikan dapat dilakukan melalui pembelajaran matematika. Matematika merupakan salah satu mata pelajaran yang wajib ditempuh dari jenjang sekolah dasar sampai perguruan tinggi. Matematika yang merupakan mata pelajaran yang dianggap sulit dan menakutkan sudah tidak selayaknya dapat diasumsikan seperti itu. Oleh karena itu, untuk menjadikan matematika yang menyenangkan, tentunya guru harus lebih kreatif dengan memanfaatkan sumber belajar yang biasanya dijumpai oleh siswa di sekitarnya yaitu melalui budayanya sendiri seperti permainan yang sering dimainkan oleh siswa, jajanan yang dibeli siswa, kerajinan tangan, bangunan dan kesenian yang sering dilihat oleh siswa. Bahkan tanpa disadari oleh siswa, mereka sudah mempelajari matematika di setiap aktivitasnya. Hal ini sesuai dengan Sembiring (2010) dan Young (2017) yang berpendapat bahwa matematika bersifat universal dimana dalam kehidupan sehari-hari tidak terlepas dari aktivitas matematika walaupun tanpa disadari oleh siswa sendiri.

Indonesia yang dikenal dengan seribu pulau yang memiliki beragam budaya, salah satunya adalah budaya sasak. Budaya sasak adalah budaya yang berasal dari pulau Lombok, Nusa Tenggara Barat. Masyarakat Lombok masih sangat kental dengan kebudayaan yang diwariskan oleh nenek moyang mereka baik dari aspek bangunan, tradisi, kesenian, kerajinan, bahkan dari makanan masih bersifat tradisional. Pada penelitiannya Supiyati et al. (2019) mengatakan bahwa banyak sekali unsur matematika yang dapat ditemukan pada budaya masyarakat sasak. Konsep dan unsur-unsur matematika tersebut dapat dijadikan sebagai sumber belajar. Pendekatan yang menyajikan produk dari suatu budaya dalam pembelajaran matematika disebut dengan etnomatematika (Albanese \& Perales, 2015; Rusliah, 2016).

Etnomatematika merupakan pembelajaran matematika dengan memasukkan unsur budaya di dalamnya. Penelitian Fauzi dan Lu'luillmaknun (2019) bahwa etnomatematika merupakan strategi pembelajaran dengan mengaitkan unsur budaya ke dalam matematika. Sedangkan menurut Nursyahidah et al. (2018) etnomatematika adalah ide matematika yang timbul dari aktivitas sehari-hari manusia dalam lingkungannya. Kemudian, lebih diperjelas lagi oleh Marsigit (2016) yang menyatakan bahwa etnomatematika merupakan ilmu yang memahami bagaimana matematika dan budaya saling berkaitan dengan tujuan dapat mengekspresikan hubungan antara keduanya. Menurut D'Ambrosio, etnomatematika dimaknai sebagai ilmu matematika yang dapat dipraktikkan pada suatu kelompok masyarakat budaya dan suku (Martyanti \& Suhartini, 2018). Berdasarkan pendapat beberapa 
ahli tersebut, dapat disimpulkan bahwa etnomatematika adalah sebuah pendekatan dalam pembelajaran matematika yang dihubungkan dengan suatu kelompok budaya sehingga dari produk budaya yang sudah ada dapat dijadikan sebagai sumber belajar matematika.

Beberapa penelitian terdahulu tentang etnomatematika diantaranya yaitu penelitian yang dilakukan oleh Muhtadi et al. (2017) tentang etnomatematika masyarakat Sunda. Pada penelitiannya ditemukan konsep matematika pada aktivitas masyarakat sunda yaitu menaksir, mengukur, dan membuat pola. Dari ketiga aktivitas ini muncul istilah kibik (satuan untuk mengukur volume), bata (satuan untuk mengukur luas lahan) dan jalurpihuntuan (modal anyaman). Kemudian penelitian Suherman (2018) ditemukan Nilai etnomatematika diperoleh dari hasil eksplorasi kerajinan tradisional Lampung bernama tapis yang diilustrasikan sebagai STEM. Tapis mencerminkan ilustrasi geometri transformasi yang menggambarkan translasi, rotasi, refleksi dan dilatasi. Lewat motif-motif tapis ini juga diperoleh penetahuan kekayaan lokal budaya Indonesia. Selanjutnya penelitian Supiyati et al.(2019) pada arsitektur bangunan pada masyarakat sasak ditemukan unsur matematika berupa pola geomteris, pengukuran.

Brandt dan Chernoff (2015) memaparkan bahwa pembelajaran yang berbasis etnomatematika sangat relevan dengan teori konstruktivisme yang dapat membantu siswa untuk meningkatkan pemahaman matematika dimana siswa dapat menghubungkan pelajaran matematika dengan pengalaman dan pengetahuannya. Pembelajaran matematika yang dikemas berdasarkan permasalahan dan pengalaman sehari-hari siswa dapat menjembatani siswa untuk lebih mudah memahami dan menemukan konsep matematika. Pada saat memahami dan mengidentifikasi masalah siswa dapat menggali informasi yang sekiranya dapat digunakan untuk menyelesaikan masalah matematika, sehingga situasi yang disajikan dapat terselesaikan berdasarkan pemahaman siswa.

Berdasarkan penjelasan para ahli di atas, bahwa pemanfaatan sumber budaya lokal sangat efektif digunakan sebagai media pembelajaran matematika untuk meningkatkan kognitif siswa. Akan tetapi kenyataannya di lapangan, masih banyak guru yang belum memanfaatkan sumber budaya untuk dijadikan media pembelajaran matematika untuk siswa sekolah dasar. Hal ini diketahui dari hasil pengamatan proses belajar mengajar yang dilakukan dan hasil wawancara kepada guru. Guru hanya menggunakan buku panduan yang diterbtikan oleh pemerintah tanpa adanya variasi pembelajaran dengan pemanfaatan sumber budaya khususnya budaya sasak, bahkan guru tidak menyadari bahwa budaya lokal sendiri banyak mengandung unsur matematika. Berdasarkan latar belakang tersebut, maka 
tujuan penelitian ini untuk mendeskripsikan hasil eksplorasi etnomatematika budaya sasak yang dapat dijadikan sebagai sumber belajar matematika.

\section{METODEPENELITIAN}

Penelitian ini merupakan jenis penelitian kualitatif eksplorasi dengan pendekatan etnografi. Gulo (2010) menyatakan bahwa peneliti dalam pendekatan etnografi menggali suatu konsep atau masalah dengan menelaah suatu kejadian atau peristiwa. Penelitian kualitatif mendeskripsikan dan memahami suatu fenomena sosial yang berada di sekitar. Penelitian ini terfokus pada bangunan tradisional, kerajinan tradisional, kesenian tradisional, dan jajanan tradisional yang berada dalam budaya masyarakat Lombok. Metode penelitian yang digunakan untuk memperoleh data berupa wawancara, eksplorasi, observasi, dan dokumentasi yang dilakukan oleh peneliti.

Instrumen pada penelitian ini terdiri dari instrumen utama dan instrumen pendukung. Instrumen utama adalah peneliti sendiri dan instrumen pendukung adalah panduan wawancara. Denzin dan Lincoln (2005) menyatakan bahwa instrumen utama pada penelitian kualitatif adalah peneliti sendiri (buman instrument). Oleh karena itu pada penelitian ini yang menjadi instrumen adalah peneliti yang secara langsung berperan di lapangan untuk mencari informasi dan pengumpul data dengan cara observasi, wawancara dan dokumentasi lapangan. Teknik analisis data yang digunakan dalam penelitian kualitatif adalah teknik triangulasi yang terdiri dari reduksi data, penyajian data, dan penarikan kesimpulan. Pada langkah reduksi data, peneliti mengubah data gambar ke bentuk tulisan serta menyeleksi data yang tidak diperlukan. Hasil wawancara, observasi, dokumentasi dan catatan lapangan yang ditemukan pada bangunan tradisional, kerajinan, tradisional, dan jajanan tradisional dieksplorasi untuk mendeskripsikan unsur-unsur matematika apa saja yang terdapat di dalamnya. Kemudian hasil reduksi, data tersebut disajikan dengan memilih unsur matematika yang tepat pada pembelajaran sekolah dasar khususnya konsep geometri yang dipelajari di sekolah dasar. Tahap terakhir penarikan kesimpulan dari hasil eksplorasi etnomatematika.

Langkah-langkah pada penelitian ini yaitu: 1) peneliti melakukan studi pendahuluan dengan mengobservasi kegiatan belajar mengajar di sekolah dasar, apakah guru sudah menyelipkan budaya lokal pada proses pembelajarannya; 2) peneliti melakukan wawancara kepada guru untuk mendapatkan data awal untuk menguatkan hasil observasi; 3) peneliti mengidentifikasi beberapa unsur budaya sebagai contoh yang digunakan pada penelitian ini, 
misalnya pada bangunan tradisional sasak (masjid kuno Bayan Beleq, bale Tani, bale Lumbung, dan bale Jajar), pada kerajinan tradisional sasak (kain tenun sesekan, tembolaq, dan cobek), pada pada kesenian tradisional sasak (gendang beleq, presean), dan jajanan tradisional sasak (cerorot, abuq, serabi, dan lupis); 4) peneliti melakukan pengambilan gambar/dokumentasi terhadap unsur budaya yang sudah diidentifikasi; 5) peneliti melakukan eksplorasi terhadap unsur budaya yang sudah dipilih untuk menggali informasi unsur matematika yang terdapat di dalamnya dengan melibatkan beberapa dosen; 6) peneliti membuat catatan kecil hasil eksplorasi sebagai konsep untuk penyusunan artikel; 7) peneliti mendeskripsikan hasil eksplorasi terhadap unsur budaya yang sudah dipilih; dan 8) peneliti memberikan kesimpulan unsur matematika yang terkandung dalam budaya lokal yang bisa dijadikan sebagai sumber belajar matematika.

\section{HASIL DAN PEMBAHASAN}

Etnomatematika menjadi perhatian luas pada akhir-akhir ini karena pembelajaran berbasis etnomatematika dapat mengubah paradigma matematika yang selama ini dianggap terlalu formal dan menakutkan bagi siswa terlebih pada anak sekolah dasar. Pembelajaran dengan mengaitkan unsur budaya yang selama ini sudah melekat pada masyarakat tentunya akan menjadi pembelajaran yang lebih bermakna. Selain itu, secara tidak lansung juga melatih anak cinta terhadap budaya mereka sendiri. Selanjutnya Rudyanto et al. (2019) mengatakan bahwa pemanfaatan produk budaya dapat dijadikan sebagai salah satu inovasi dalam pembelajaran matematika agar menjadi lebih efektif sehingga tujuan belajar matematika dapat dicapai. Unsur budaya masyarakat sasak dijadikan objek pembelajaran sangat banyak misalnya bangunan tradisional, kerajinan tradisional, kesenian tradisional, dan jajanan tradisional.

\section{Eksplorasi Etnomatematika pada Bangunan Tradisional Sasak}

Peninggalan bangunan tradisional sasak yang belum dipengaruhi oleh perkembangan zaman masih banyak dijumpai di Pulau Lombok yaitu di desa Sade, desa Ende yang berada di Kebupaten Lombok Tengah, dan desa Bayan di Kabupaten Lombok Utara. Desa Sade, Ende, dan Bayan merupakan desa yang kental dengan budaya masyarakat sasak yang diwariskan secara turun temurun oleh lelulurnya. Bangunan yang bisa dijumpai pada desa tersebut misalnya masjid kuno bayan beleq (Lombok Utara), rumah tempat tinggal atau yang disebut masyarakat sasak bale. Bale masyarakat sasak sendiri beragam jenis yaitu bale lumbung, 
bale tani, dan bale jajar. Bangunan tradisional sasak ini dibuat menggunakan bahan material alam berupa batu, kayu, bambu, dan alang-alang sebagai atap bangunan.

Tabel 1. Etnomatematika pada Bangunan Tradisional Sasak

\begin{tabular}{|c|c|c|}
\hline Nama Bangunan & Penjelasan & Konsep Matematika \\
\hline Masjid Kuno $B$ & $\begin{array}{l}\text { Masjid kuno Bayan } \text { Beleq } \\
\text { merupakan salah satu warisan } \\
\text { budaya dari para tokoh } \\
\text { penyebar agama islam pada } \\
\text { masyarakat sasak. Masjid kuno } \\
\text { ini berada di Kabupaten } \\
\text { Lombok Utara, Kecamatan } \\
\text { Bayan. Ukuran Masjid ini } \\
\text { berukuran 9x9 meter persegi } \\
\text { dengan dinding rendah dari } \\
\text { anyaman bambu. }\end{array}$ & $\begin{array}{l}\text { Unsur matematika pada } \\
\text { masjid kuno Bayan Beleq yaitu } \\
\text { bentuk atap menyerupai } \\
\text { trapesium dan segitiga, } \\
\text { dinding masjid berbentuk } \\
\text { persegi panjang. Di dalam } \\
\text { masjid terdapat } 4 \text { buah tiang, } \\
\text { dan } 1 \text { bedug yang berbentuk } \\
\text { silinder/ tabung. }\end{array}$ \\
\hline
\end{tabular}
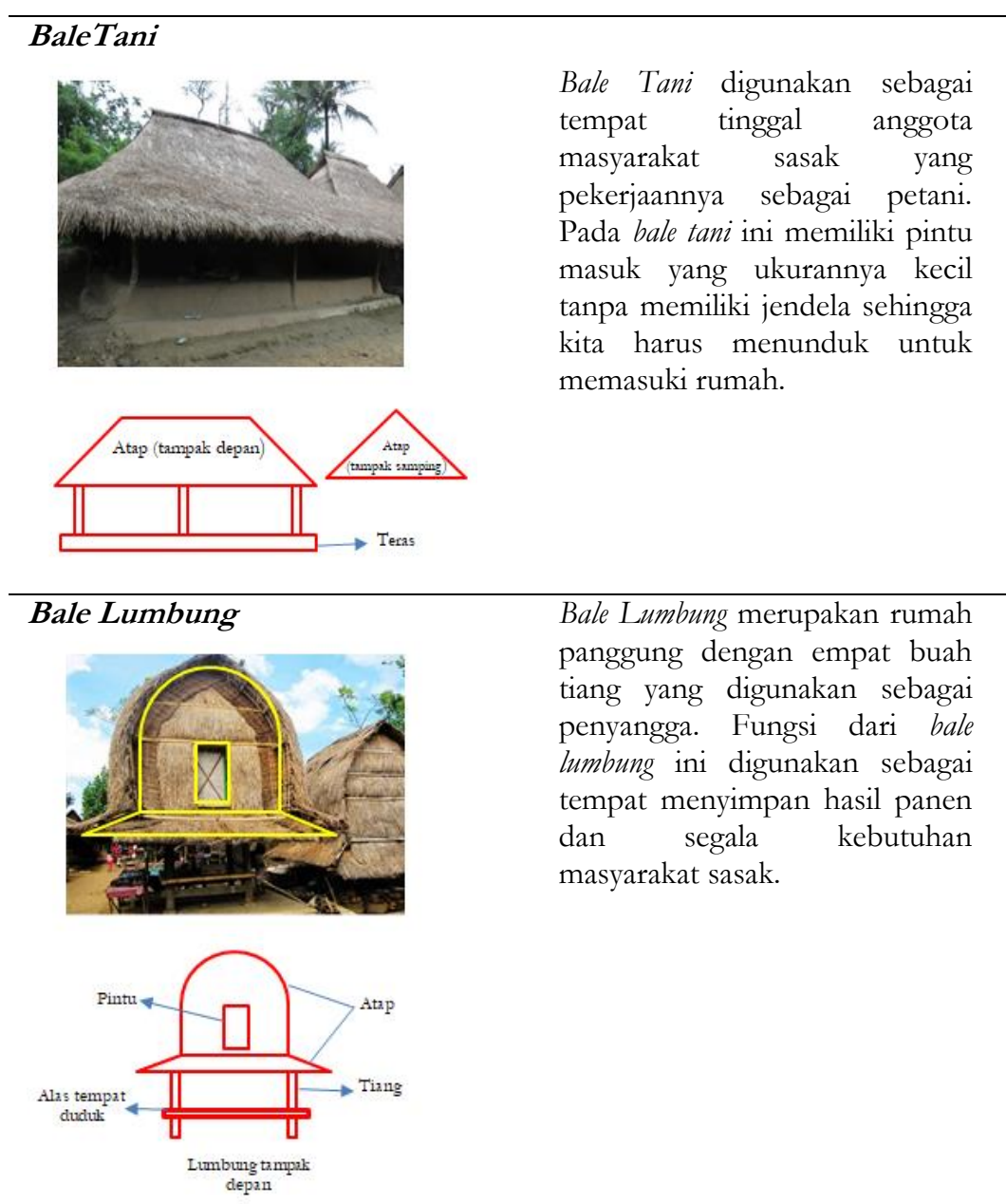

Bale Jajar merupakan tempat tinggal bagi anggota suku sasak yang ekonominya menengah ke atas. Bale Jajar mirip dengan Bale Tani tetapi ukurannya lebih besar dimana di dalam rumah
Unsur matematika yang terdapat pada bangunan tradisional bale tani yaitu bagian atap berbentuk trapesium (tampak depan), segitiga (tampak samping). Sedangkan, dinding dan pintu, berbentuk persegi panjang.
Atap utama bale lumbung berbentuk setengah elips, dan atap yang melebar ke samping berbentuk trapesium. Pintu tempat memasukkan hasil panen berbentuk persegi panjang. Tempat duduk (alas) yang berada di bawah lumbung berbentuk persegi, dan 4 buah tiang penyangga terbuat dari kayu yang berbentuk silinder 


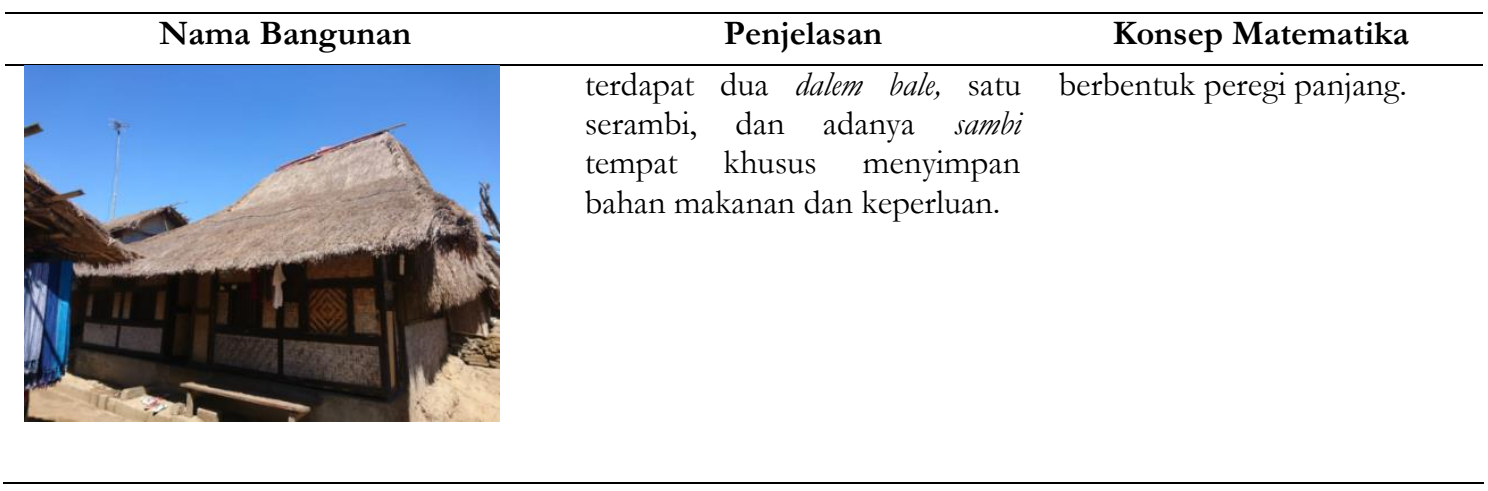

\section{Eksplorasi Etnomatematika pada Kerajinan Tradisional Sasak}

Mata pencaharian masyarakat Lombok sebagian besar dengan Bertani. Akan tetapi tidak sedikit pula masyarakat sasak Lombok yang memenuhi perekonomiannya sebagai pengrajin yang dijadikan sebagai pekerjaan sampingan. Dari hasil kerajinan inilah yang dijadikan untuk memenuhi kebutuhan sehari-hari. Kerajinan yang paling khas dari Lombok adalah kerajinan kain tenun Sesekan yang dibuat dari bahan alami dan alat tradisional. Kerajinan tenun sesekan ini diperuntukkan untuk perempuan, bahkan kerajinan ini dijadikan sebagai pekerjaan utama bagi kaum perempuan masyarakat sasak. Dari hasil wawancara dengan tokoh masyarakat desa Sade, kaum perempuan yang ada di desa tersebut diharuskan bisa menjadi pengrajin kain sesekan. Hal tersebut dikarenakan hasil dari kerajinannya itu bisa digunakan untuk menambah perekonomian keluarga sembari menunggu hasil panen tani yang dikerjakan oleh kaum laki-laki. Selain terkenal dengan kerajinan kain tenun sesekan, masyarakat Lombok juga terkenal dengan kerajinan anyaman bambu dan gerabahnya. Salah satu pusat kerajinan bambu berada di daerah Gunung Sari, Kabupaten Lombok Barat, dan untuk kerajinan gerabah di daerah Masbagik, Kabupaten Lombok Timur.

Kerajinan-kerajinan tradisional tersebut bisa digunakan sebagai sumber belajar matematika bagi siswa. Selain bermanfaat untuk pengenalan budaya kepada siswa, juga bisa bermanfaat dalam pembelajaran sehingga pembelajaran lebih efektif dan menyenangkan. Berikut hasil eksplorasi etnomatematika pada beberapa kerajinan tradisional.

Tabel 2. Etnomatematika pada Kerajinan Tradisional

\begin{tabular}{lll}
\hline Nama Kerajinan & \multicolumn{1}{c}{ Penjelasan } & Konsep Matematika \\
\hline Kain Tenun Sesekan & Kerajinan kain tenun sesekan & Hasil eksplorasi terhadap motif \\
& dibuat oleh kaum perempuan kain tenun sesekan mengandung \\
& dengan peralatan yang masih unsur geometri bidang berupa \\
& tradisional. Kain tenun sesekan persegi, persegi panjang, belah \\
& ini banyak dijumpai di desa Sade, ketupat, jajargenjang, segitiga, \\
& Ende, Loyok, Sukerere, dan layang-layang, dan terdapat \\
& banyak lagi daerah lain konsep kesebangunan. \\
& penghasil kain tenun sesekan. \\
\hline
\end{tabular}




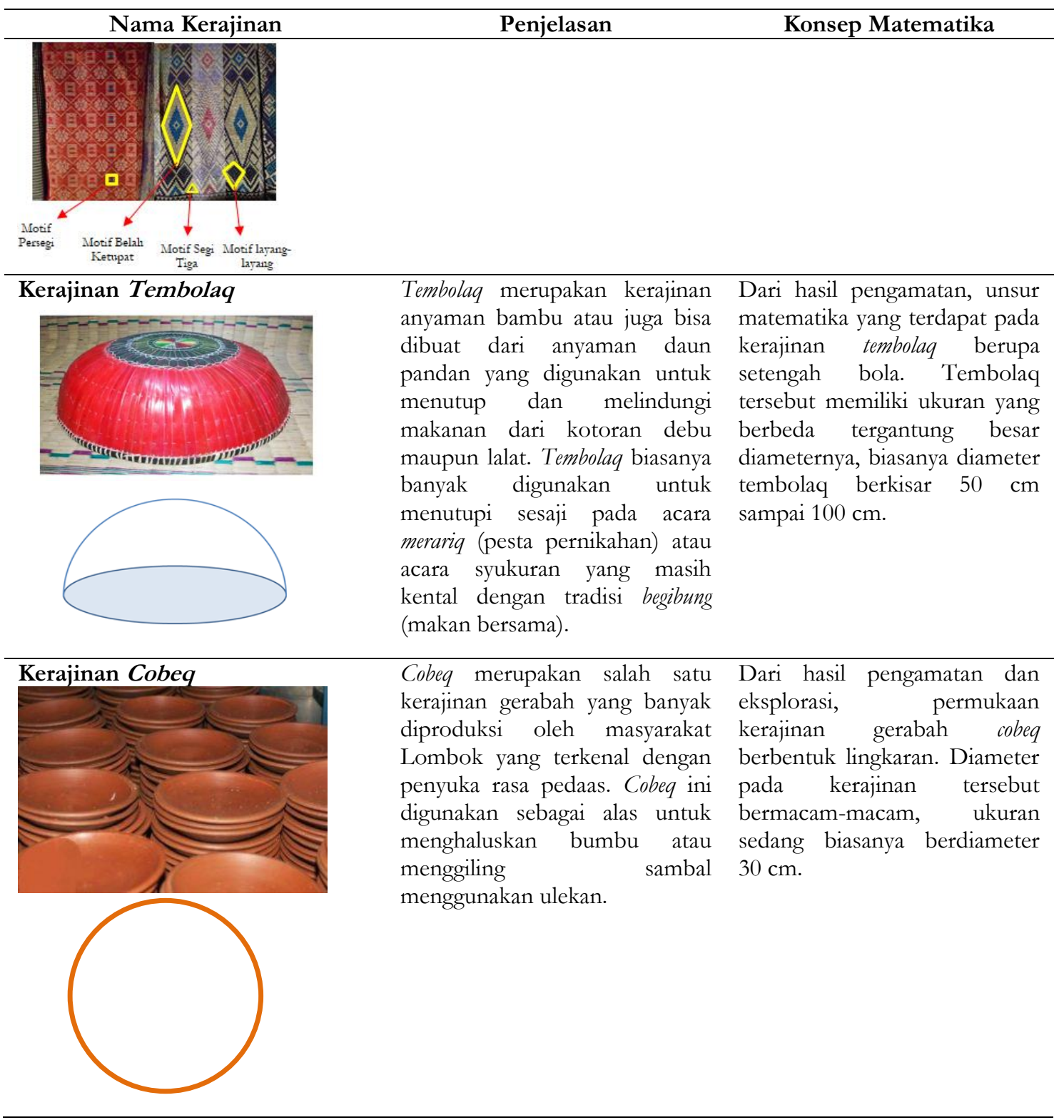

\section{Eksplorasi Etnomatematika pada Kesenian Tradisional Sasak}

Kesenian tradisional merupakan bagian dari budaya yang digunakan sebagai sarana untuk mengekspresikan rasa keindahan dari jiwa masyarakat setempat. Kesenian tradisional ini membuat masyarakat dapat mempererat tali silaturahmi dan solidaritas. Pulau Lombok yang kaya akan budaya memiliki banyak kesenian yang dapat menarik para wisatawan baik wisatawan lokal maupun mancanegara. Kesenian tradisional di Lombok yang dapat menandakan kekhasan masyarakat sasak adalah kesenian Gendang Beleq dan Peresean. Berdasarkan hasil pengamatan dan eksplorasi terhadap kesenian tradisional sasak, kesenian Gendang Beleq dan Peresean dapat dijadikan sebagai sumber belajar matematika. Berikut hasil eksplorasi etnomatematika dari kesenian Gendang Beleq dan Peresean. 
Tabel 3. Etnomatematika pada Kesenian Tradisional Sasak

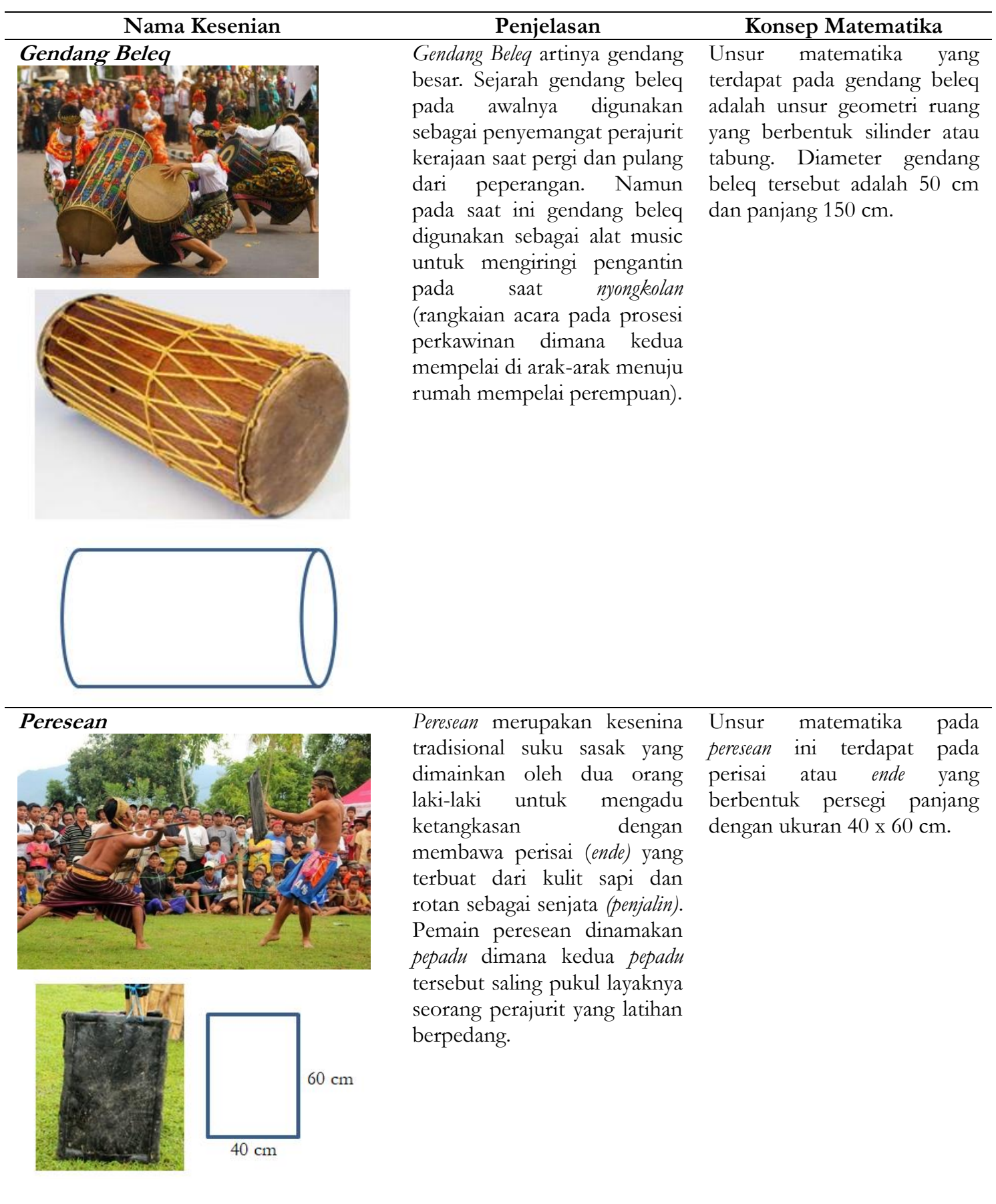

\section{Eksplorasi Etnomatematika pada Jajanan Tradisional Sasak}

Berdasarkan hasil pengamatan yang dilakukan, secara fisik jajanan tradisional khususnya yang beredar pada masyarakat sasak memiliki bentuk seperti geometri ruang dan bidang. Unsur matematika yang terdapat pada jajanan tradisional ini maka bisa dijadikan sebagai sumber belajar matematika. Pada masyarakat Lombok, jajanan tradisional yang masih mempertahankan keasliannya dari segi rasa, bentuk, bahan, dan cara pengolahaannya 
masih banyak dijumpai. Misalnya jajanan tradisional cerorot, abuq, serabi, pangan lupis dan berbagai jenis jajanan lainnya. Berikut ini hasil eksplorasi terhadap beberapa jajanan tradisional yang sering dijumpai di pasar.

Tabel 4. Etnomatematika pada Jajanan Tradisional

\begin{tabular}{lll}
\hline Nama Jajanan & \multicolumn{1}{c}{ Penjelasan } & \multicolumn{2}{c}{ Konsep Matematika } \\
\hline Cerorot & $\begin{array}{l}\text { Cerorot merupakan jajanan Unsur matematika yang } \\
\text { tradisional yang terbuat dari terdapat pada jajanan } \\
\text { tepung, santan, dan tradisional cerorot adalah } \\
\text { dicampurkan dengan gula unsur geometri ruang berupa } \\
\text { merah. Bungkus atau wadahnya kerucut. } \\
\text { terbuat dari daun kelapa yang } \\
\text { dibentuk menyerupai kerucut. }\end{array}$
\end{tabular}
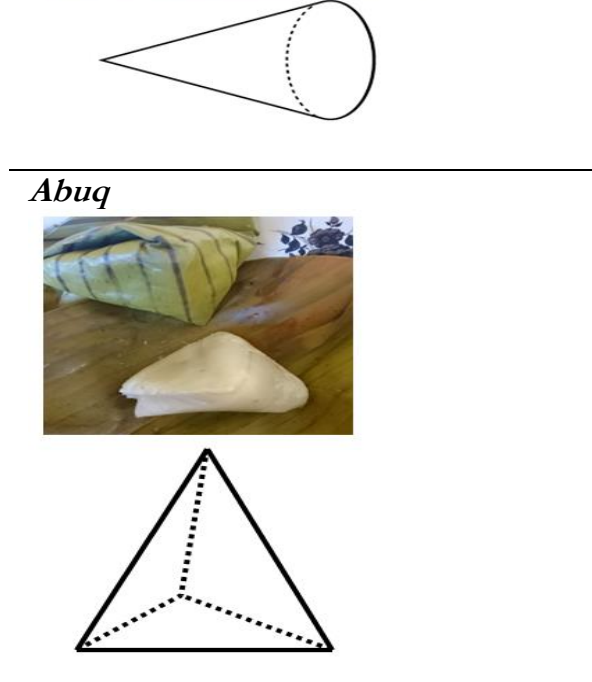

$\begin{array}{llll}\text { Jajanan tradisional abuq } & \text { Unsur matematika berupa } \\ \text { merupakan salah satu jajanan } & \text { geometri ruang berupa limas } \\ \text { tradisional yang sering disajikan } & \text { segitiga. Akan tetapi tidak } \\ \text { pada saat acara Maulid. Abuq } & \text { sedikit juga yang membuat } \\ \text { terbuat dari ketan yang } & \text { kue abuq dengan bentuk } \\ \text { dicampur dengan parutan persegi, segitiga, dan lainnya. }\end{array}$

kelapa, dan di dalam kue abuq diisi dengan gula merah. Kue Abuq dibungkus dengan daun pisang kemudian dikukus.

Salah satu jajanan tradisional Unsur matematika pada
khas Lombok adalah serabi yang jajanan tradisional serabi
terebuat dari adonan beras adalah geometri bidang
ketan dan santan. Serabi berupa lingkaran.
biasanya disajikan
menggunakan parutan kelapa
diatasnya dan taburkan gula
merah cair.


Hasil eksplorasi produk-produk budaya yang dilakukan selama ini sangat memungkinkan untuk dimanfaatkan dalam pembelajaran matematika. Rudyanto et al., (2019) memaparkan bahwa trend pembelajaran yang berbasis etnomatematika merupakan tantangan yang dijadikan pegangan dalam pembelajaran matematika yang memberikan kesempatan seluas-luasnya bagi siswa untuk membangun pengetahuan dan kemampuan siswa. Selanjutnya Martyanti \& Suhartini (2018) menyimpulkan bahwa pembelajaran matematika yang dikemas berdasarkan konteks budaya dapat digunakan sebagai jembatan bagi siswa untuk menumbuhkan konsep matematika. Hasil penelitian Supiyati et al. (2019) menunjukkan beberapa konsep dan unsur matematika pada arsitektur budaya sasak yaitu konsep pengukuran dan bentuk geomtri. Sedangkan pada penelitian ini dihasilkan bentukbentuk geometri yang dapat dijadikan sumber belajar bagi sekolah dasar. Eksplorasi budaya sasak dapat dijadikan sebagai bahan untuk belajar matematika pada materi geometri untuk sekolah dasar. Selain dapat membentuk pemahaman konsep geometri, siswa juga dapat mengenal budayanya sendiri yang sudah mulai terlupakan dengan perkembangan zaman yang semakin maju. Hal ini senada dengan yang dipaparkan oleh Massarwe et al.(2013) bahwa pembelajaran matematika dengan pendekatan etnomatematika memungkinkan terjadinya perubahan konseptual dalam persepsi geometri dan siswa lebih menyadari akan budaya di lingkungan sekitar.

Berdasarkan hasil penelitian eksplorasi etnomatematika pada beberapa unsur budaya sasak ini dapat dijadikan sebagai sumber belajar matematika yang menyenangkan. Siswa sekolah dasar akan lebih tertarik jika media dan sumber belajar yang digunakan merupakan benda-benda yang terdapat di sekitar mereka. Selain menjadikan pembelajaran matematika yang menyenangkan, siswa dapat mengenalkan dan melestarikan budaya sekitar sehingga budaya kita sendiri tidak ditenggelamkan oleh zaman yang semakin maju. Hasil eksplorasi unsur budaya bangunan, kerajinan, kesenian, dan jajanan tradisional sasak dapat ditemukan unsur matematika berupa geometri bidang dan geometri ruang. Berdasarkan temuantemuan tersebut dapat digunakan sebagai media dan sumber belajar matematika oleh guru pada materi geometri sekolah dasar.

\section{SIMPULAN DAN SARAN}

Melimpahnya produk tradisional budaya sasak sangat berperan penting dalam penerapannya sebagai media pembelajaran, khusunya pada pembelajaran matematika di sekolah. Produk tradisional budaya sasak juga berperan dalam pengenalan dan 
pemeliharaan budaya yang sudah mulai ditinggalkan oleh generasi muda. Berdasarkan analisis hasil eksplorasi dan pembahasan di atas, maka dapat disimpulkan bahwa: 1) konsepkonsep matematika yang terdapat pada bangunan tradisonal sasak adalah: persegi panjang, trapesium, segitiga, silinder. 2) Konsep-konsep matematika dari hasil analisis eksplorasi terhadap kerajinan tradisional yang berupa kain sesekan, tembolaq dan cobeq adalah: persegi panjang, persegi, belah ketupat, jajargenjang, segitiga, layang-layang, lingkaran, setengah bola, dan konsep kesebangunan. 3) Hasil eksplorasi pada kesenian tradisional sasak terdapat konsep matematika berupa silinder dan persegi panjang. 4) Konsep matematika dari hasil eksplorasi pada jajanan tradisional sasak adalah: kerucut pada jajanan cerorot, limas segitiga pada jajanan abuq, lingkaran pada jajanan serabi, dan lupis berbentuk segitiga, lingkaran.

Saran yang dapat diberikan oleh peneliti yaitu: 1) untuk guru, sebaiknya unsur-unsur budaya lokal dapat dijadikan sebagai sumber belajar matematika agar menjadi proses belajar mengajar yang menyenangkan dan tidak monoton terpaku pada satu buku panduan; 2) untuk peneliti selanjutnya dapat mengembangkan dan lebih menggali lebih dalam lagi unsur matematika yang terkandung dalam budaya sekitar yang terdapat di daerah-daerah lain.

\section{DAFTAR RUJUKAN}

Albanese, V., \& Perales, F. J. (2015). Enculturation with Ethnomathematical Microprojects: From Culture to Mathematics. Journal of Mathematics \& Culture, 9(1), 1-11.

Brandt, A., \& Chernoff, E. (2015). The Importance of Ethnomathematics in the Math Class. Obio Journal of School Mathematics, 71, 31-36.

Budiarto, M. T. (2016). Peran Matematika dan Pembelajarannya Dalam Mengembangkan Kearifan Budaya Lokal Mendukung Pendidikan Karakter Bangsa. Prosiding Seminar Nasional 2016 Program Studi Pendidikan Matematika Universitas Madura, 1-11.

Denzin, N. K., \& Lincoln, Y. S. (2005). Handbook Of Qualitative Research Third Edition. Jakarta: Sage Publicatio, Inc.

Fauzi, A., \& Lu'luillmaknun, U. (2019). Etnomatematika Pada Permainan Denklaq Sebagai Media Pembelajaran Matematika. AKSIOMA: Jurnal Program Studi Pendidikan Matematika, 8(3), 408-419.

Gulo, W. (2010). Research Methodology. Jakarta: PT. Grasindo.

Junaidi, L. A. (2015). Ethnomathematics Sasak: Geometry Concepts In Community Life Banyumulek West Lombok. International Conference On Mathematics, Science, and Education (ICMSE), 27-30.

Marsigit. (2016). Pengembangan Pembelajaran Matematika Berbasis Etnomatematika. Semnas Matematika Dan Pendidikan Matematika: Etnomatematika, Matematika Dalam Perspektif Sosial Dan Budaya, 1-38.

Martyanti, A., \& Suhartini, S. (2018). Etnomatematika: Menumbuhkan Kemampuan 
Berpikir Kritis Melalui Budaya Dan Matematika. IndoMath: Indonesia Mathematics Education, 1(1), 35. https://doi.org/10.30738/indomath.v1i1.2212

Massarwe, K., Verner, I., \& Bshouty, D. (2013). Ethnomathematics and Multi-Cultural Education: Analysis and Construction of Geometric Ornaments Journal of Mathematics and Culture. Journal of Chemical Information and Modeling, 53(9), 16891699. https://doi.org/10.1017/CBO9781107415324.004

Muhtadi, D., Sukirwan, Warsito, \& Prahmana, R. C. I. (2017). Sundanese Ethnomathematics: Mathematical Activities in Estimating, Measuring, and Making Patterns. Journal on Mathematics Education, 8(2), 185-198. https://doi.org/10.1017/cbo9780511600036.030

Nursyahidah, F., Saputro, B. A., \& Rubowo, M. R. (2018). A Secondary Student's Problem Solving Ability in Learning Based on Realistic Mathematics with Ethnomathematics. JRAMathEdu (Journal of Research and Advances in Mathematics Education), 3(1), 13-24. https://doi.org/10.23917/jramathedu.v3i1.5607

Pradana, P. H. (2016). Penerapan Pendidikan Karakter Dalam Pembelajaran Matematika. Seminar Nasional Pendidikan "Pengembangan Pendidikan Karakter Bangsa Berbasis Kearifan Lokal Dalam Era MEA", 1, 81-85.

Rudyanto, H. E., Kartikasari, A., \& Pratiwi, D. (2019). Etnomatematika Budaya Jawa: Inovasi Pembelajaran Matematika Di Sekolah Dasar. Jurnal Bidang Pendidikan Dasar, 3(2), 25-32. https://doi.org/10.21067/jbpd.v3i2.3348

Rusliah, N. (2016). Pendekatan Etnomatematika dalam Permainan Tradisional Anak di Wilayah Kerapatan Adat Koto Tengah Kota Sungai Penuh Propinsi Jambi. Proceedings of The International Conference on University-Community Engagement, 715-726. http://digilib.uinsby.ac.id/7435/1/Nur Rusliah.pdf

Sembiring, R. K. (2010). Pendidikan Matematika Realistik Indonesia (PMRI): Perkembangan dan tantangannya. Journal on Mathematics Education, 1(1), 11-16. https://doi.org/10.22342/jme.1.1.791.11-16

Suherman, S. (2018). Ethnomathematics: Eksploration of Traditional Crafts Tapis Lampung as Ilustration of Science, Technology, Engineering, and Mathematics (STEM). Eduma: Mathematics Education Learning and Teaching, 7(2). https://doi.org/10.24235/eduma.v7i2.3085

Supiyati, S., Hanum, F., \& Jailani. (2019). Ethnomathematics in sasaknese architecture. Journal on Mathematics Education, 10(1), 47-57. https://doi.org/10.22342/jme.10.1.5383.47-58

Young, J. R. (2017). Technology Integration in Mathematics Education: Examining the Quality of Meta-Analytic Research. International Journal on Emerging Mathematics Education, 1(1), 71. https://doi.org/10.12928/ijeme.v1i1.5713 